\section{Euploid Endosperm of Triploid $x$ Diploid/tetraploid Crosses Results in Aneuploid Embryo Survival in Lilium}

\author{
Shujun Zhou', Guixue Zhou, and Kehu Li
}

Department of Horticulture, College of Agriculture and Biotechnology, Zhejiang University, Key Laboratory of Horticultural Plant Growth, Development and Quality Improvement, Ministry of Agriculture, The People's Republic of China

Additional index words. secondary nucleus, Fritillaria-type embryo sac, Polygonum-type embryo sac, interploid crosses, megasporogenesis

\begin{abstract}
The main objective of the present study was to identify chromosome number variation in the progenies from triploid $\times$ diploid/tetraploid $(3 x \times 2 \times / 4 x)$ crosses in Lilium to analyze the survival of aneuploid embryos from $3 x \times 2 x / 4 x$ crosses and the potential significance of triploid for lily breeding. Two male-sterile autotriploid Asiatic lily cultivars were crossed with four diploid and/or two autotetraploid Asiatic cultivars. The results showed that the fruits of all triploid $\times$ diploid/tetraploid $(3 x \times 2 x / 4 x)$ crosses fully developed, and seedlings were obtained from the $3 x \times 2 x / 4 x$ crosses, indicating that malesterile autotriploid lilies can be used as female parents. Chromosome preparation showed that the progenies of the $3 x \times 2 x / 4 x$ are predominantly aneuploid. Based on megasporogenesis, we deduce that the endosperm of $3 x \times 2 x$ is $7 x$ and that of $3 x \times 4 x$ is $8 x$ in Lilium and conclude that the aneuploid embryo survival of $3 x \times 2 x / 4 x$ in Lilium is the result of the euploid endosperm. Lily is usually propagated by scaling or tissue culture; therefore, aneuploids obtained from triploid $\times$ diploid/tetraploid lilies would be a good source for cultivar breeding.
\end{abstract}

Lily is an important ornamental crop worldwide. Modern lily cultivars originated from wild species of the genus Lilium L. of the family Liliaceae (McRae, 1990, 1998; Van Tuyl et al., 2000, 2002a, 2002b). Most of them are classified into four groups, Asiatic, Longiflorum, Oriental and Trumpet, each representing one lily genome $(\mathrm{A}, \mathrm{L}, \mathrm{O}$, and $\mathrm{T}$, respectively). Wild species of Lilium are diploid $(2 n=2 x=24)$, except $L$. lancifolium Thunb., which has some triploid taxa (Kim et al., 2006). Triploid lilies $(2 n=3 x=36)$ are also produced by diploid $\times$ tetraploid crosses or $2 n$ gametes (Barba-Gonzalez et al., 2004, 2005a, 2005b; Lim et al., 2000). Based on their genome composition, triploid lilies with three identical genomes are regarded as autotriploid, e.g., AAA, whereas others such as LAA and AOA are allotriploid. Both types have abnormal meiosis during gamete formation, causing sterility, which blocks further introgression breeding. However, some lily allotriploid $\times$ diploid/tetraploid crosses have been successful, and their progenies have been analyzed for their genome com-

Received for publication 21 Dec. 2010. Accepted for publication $7 \mathrm{Feb} .2011$

We thank Zhongshan Gao and Liumin Fan for reading the manuscript and Shirley Burgess for English correction.

We thank the National Natural Science Foundation of China (30871730) and the Fundamental Research Funds for Central Universities for financial support.

${ }^{1}$ To whom reprint requests should be addressed; e-mail zhou2007@zju.edu.cn.
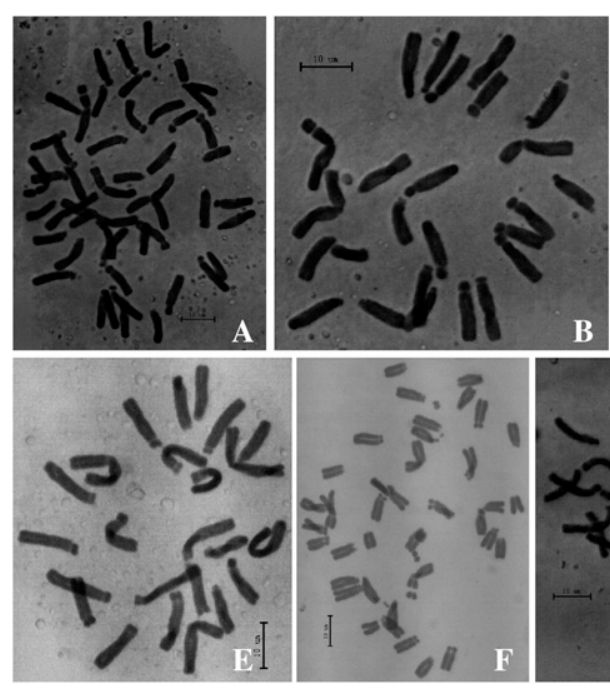

position and intergenomic recombination using genomic in situ hybridization (BarbaGonzalez et al., 2006; Khan et al., 2009; Lim et al., 2003; Xie et al., 2010; Zhou, 2007). Nevertheless, few lily autotriploid $x$ diploid/tetraploid $(3 x \times 2 x / 4 x)$ crosses have been reported. In the present study, we made $3 x \times 2 x / 4 x$ crosses of Asiatic lilies to identify variation of their chromosome number and discussed why the aneuploid embryos from the $3 x \times 2 x / 4 x$ crosses were able to survive and the potential significance of triploid for lily breeding.

\section{Materials and Methods}

Plant materials. Eight Asiatic lily cultivars were used (Table 1). Six were bought from the Hongyue Flower Company, Zhejiang Province, China, and two were supplied courtesy of the Yunnan Flower Institute, Yunnan Province, China. In Mar. 2009, the cultivars were planted under natural light with regular watering in a glass greenhouse at Zhejiang University, China.

Chromosome preparation for the cultivars. Chromosome preparation was according to Zhou et al. (2008) with minor modifications. When lily roots were $\approx 1 \mathrm{~cm}$ long, they were cut off and pretreated with $0.7 \mathrm{~mm}$ cycloheximide (Amresco) at room temperature for $4 \mathrm{~h}$ and then fixed in ethanol: acetic acid (Sinopharm Chemical Reagent Co., Ltd.) (3:1) overnight. The root tips were softened with a $1 \%(\mathrm{w} / \mathrm{v})$ cellulase RS (Dutchefa Bioche$\mathrm{mie})$ and $1 \%(\mathrm{w} / \mathrm{v})$ pectinase Y23 (Dutchefa Biochemie) mix at $37{ }^{\circ} \mathrm{C}$ for $\approx 1 \mathrm{~h}$. The meristem was mixed with a drop of $1 \%$ acetocarmine (Fluka) and squashed on a glass slide. Each slide was checked with an Olympus microscope (BH-2) and metaphase cells were photographed with $40 \times$ objective oil lens and a charge-coupled device camera. Usually, more than five cells with good metaphase were used to determine the chromosome numbers of the cultivars.
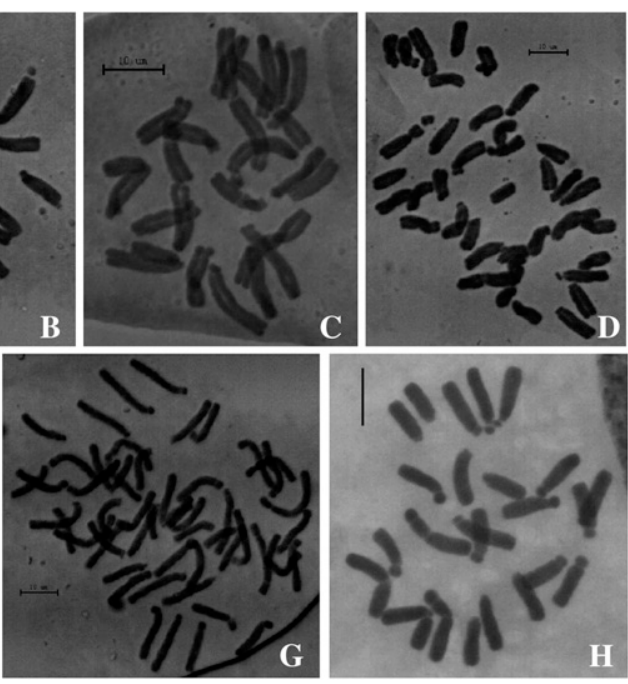

Fig. 1. The chromosomes at mitotic metaphase of the lily cultivars. (A) $\mathrm{AAAA}^{001}(2 n=4 x=48),(\mathbf{B}) \mathrm{AA}^{002}$ $(2 n=2 x=24),(\mathbf{C}) \mathrm{AA}^{003}(2 n=2 x=24),(\mathbf{D}) \mathrm{AAA}^{004}(2 n=3 x=36),(\mathbf{E}) \mathrm{AA}^{005}(2 n=2 x=24),(\mathbf{F})$ $\operatorname{AAA}^{18}(2 n=3 x=36),(\mathbf{G}) \mathrm{AAAA}^{007}(2 n=4 x=48)$, and $(\mathbf{H}) \mathrm{AA}^{26}(2 n=2 x=24)$. Bar $=10 \mu \mathrm{m}$. 


\begin{tabular}{|c|c|c|c|c|c|c|c|c|}
\hline \multirow[b]{2}{*}{ Code } & \multirow[b]{2}{*}{ Female } & \multirow[b]{2}{*}{$x$} & \multirow[b]{2}{*}{ Male } & \multirow[b]{2}{*}{ Flowers (no.) } & \multirow[b]{2}{*}{ Fruits (no.) } & \multicolumn{2}{|c|}{ Condition of endosperm ${ }^{z}$} & \multirow[b]{2}{*}{ Seedlings (no. } \\
\hline & & & & & & Em. S. (no.) & Em. (no.) & \\
\hline 090088 & $\mathrm{AAA}^{004}$ & & $\mathrm{AA}^{002}$ & 11 & 8 & 15 & 8 & 8 \\
\hline 090047 & $\mathrm{AAA}^{004}$ & & $\mathrm{AA}^{003}$ & 4 & 4 & 12 & 2 & 0 \\
\hline 090044 & $\mathrm{AAA}^{004}$ & & $\mathrm{AA}^{26}$ & 4 & 4 & 18 & 7 & 7 \\
\hline 090010 & $\mathrm{AAA}^{18}$ & & $\mathrm{AA}^{26}$ & 4 & 2 & 8 & 13 & 8 \\
\hline Subtotal & & & & 28 & 23 & 77 & 37 & 38 \\
\hline 090046 & $\mathrm{AAA}^{004}$ & & $\mathrm{AAAA}^{001}$ & 5 & 5 & 15 & 15 & 9 \\
\hline 090045 & $\mathrm{AAA}^{004}$ & & AAAA $^{007}$ & 4 & 4 & 22 & 35 & 32 \\
\hline 090089 & $\mathrm{AAA}^{004}$ & & AAAA $^{007}$ & 14 & 11 & 17 & 40 & 55 \\
\hline Subtotal & & & & 23 & 20 & 54 & 90 & 96 \\
\hline
\end{tabular}

${ }^{2}$ Embryo sacs or embryos could be isolated for culture only from ovules with well-developed endosperm.
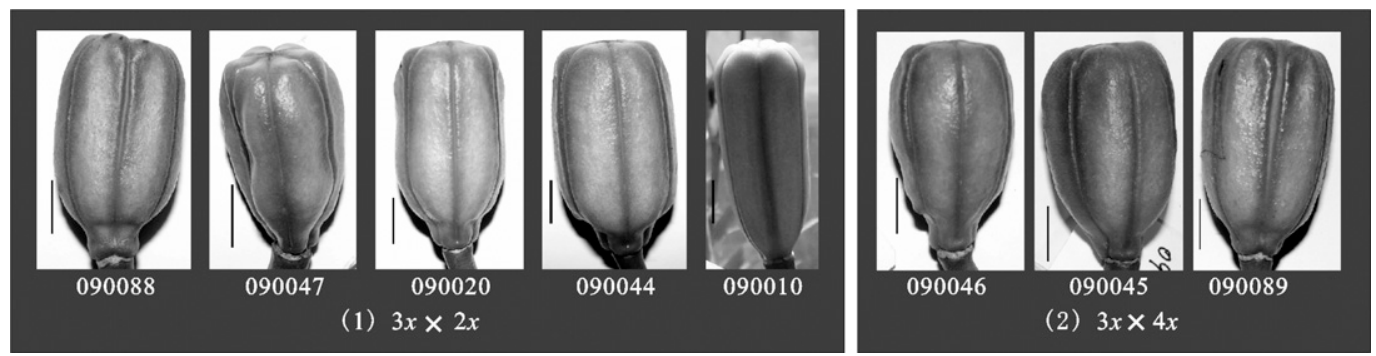

Fig. 2. The fruits of $3 x \times 2 x / 4 x$ crosses collected for embryo rescue. (1) $3 x \times 2 x$ crosses and (2) $3 x \times 4 x$ crosses. All appeared to develop well. Bar $=1 \mathrm{~cm}$.

Pollen germination. Pollen from open anthers was scattered on pollen germination medium containing $100 \mathrm{~g} \cdot \mathrm{L}^{-1}$ sucrose (Sinopharm Chemical Reagent Co., Ltd.), $5 \mathrm{~g} \cdot \mathrm{L}^{-1}$ bacteriological agar (Sinopharm Chemical Reagent Co., Ltd.), $20 \mathrm{mg} \cdot \mathrm{L}^{-1}$ boric acid (Shanghai Yunling Refinery, China), and $200 \mathrm{mg} \cdot \mathrm{L}^{-1}$ $\mathrm{Ca}\left(\mathrm{NO}_{3}\right)_{2}$ (Shanghai Naihui Pengzheng-Yingfang Refinery, China) in a petri dish and kept at $25^{\circ} \mathrm{C}$ overnight. Three to five easily countable scopes, containing $\approx 150$ to 400 pollen grains, were observed under a stereo microscope (OPLENIC-SZM745T) to calculate the percentage of pollen germination.

Pollination. Anthers of seed plants were removed before anthesis. Styles were pollinated by hand and wrapped in aluminum foil to avoid contamination by other pollen.

Embryo rescue. Fruits were harvested when they became soft or yellowing after pollination. In a laminar air flow cabinet, each fruit was sterilized using $80 \%$ ethanol (Sinopharm Chemical Reagent Co., Ltd.), cut open, and the seeds put in a sterile petri dish. The seedcoats were carefully removed, and the embryo sacs or embryos put on lily embryo rescue medium $(\mathrm{pH}=5.8)$ containing $2.2 \mathrm{~g} \cdot \mathrm{L}^{-1}$ Murashige and Skoog (MS) medium (Duthefa Biochemie), $60 \mathrm{~g} \cdot \mathrm{L}^{-1}$ sucrose, and $4 \mathrm{~g} \cdot \mathrm{L}^{-1}$ gelrite (Dutchefa Biochemie). They germinated in a dark chamber at $25{ }^{\circ} \mathrm{C}$ for 40 to $60 \mathrm{~d}$ and then were transferred to lily propagation medium $(\mathrm{pH}=5.8)$ containing $2.2 \mathrm{~g} \cdot \mathrm{L}^{-1}$ MS medium, $50 \mathrm{~g} \cdot \mathrm{L}^{-1}$ sucrose, and $4 \mathrm{~g} \cdot \mathrm{L}^{-1}$ gelrite at $25{ }^{\circ} \mathrm{C}$ and $40 \mu \mathrm{mol} \cdot \mathrm{m}^{-2} \cdot \mathrm{s}^{-1}$ light intensity for $\approx 10$ weeks.
Table 3. Chromosome numbers of the progenies obtained from autotriploid $\times$ diploid/tetraploid crosses showing the contribution by the male and the female.

\begin{tabular}{|c|c|c|c|c|}
\hline Type of crosses & Progeny code & $\begin{array}{c}\text { Chromosome } \\
\text { numbers }\end{array}$ & $\begin{array}{c}\text { Contributed by } \\
\text { male }^{z}\end{array}$ & $\begin{array}{c}\text { Contributed by } \\
\text { female }^{\mathrm{y}}\end{array}$ \\
\hline \multirow{5}{*}{$\mathrm{AAA}^{004} \times \mathrm{AA}^{005}$} & $090020-4$ & 39 & 12 & 27 \\
\hline & $090020-5$ & 29 & 12 & 17 \\
\hline & 090020-11 & 33 & 12 & 21 \\
\hline & $090020-15$ & 27 & 12 & 15 \\
\hline & Average & 32 & 12 & $20.0 \mathrm{a}^{\mathrm{x}}$ \\
\hline \multirow[t]{5}{*}{$\mathrm{AAA}^{18} \times \mathrm{AA}^{26}$} & 090010-1 & 28 & 12 & 16 \\
\hline & 090010-4 & 29 & 12 & 17 \\
\hline & 090010-5 & 28 & 12 & 16 \\
\hline & 090010-6 & 32 & 12 & 20 \\
\hline & Average & 29.3 & 12 & $17.3 \mathrm{a}$ \\
\hline \multirow[t]{7}{*}{$\mathrm{AAA}^{004} \times \mathrm{AAAA}^{001}$} & 090046-2 & 40 & 24 & 16 \\
\hline & 090046-4 & 45 & 24 & 21 \\
\hline & 090046-5 & 45 & 24 & 21 \\
\hline & 090046-6 & 42 & 24 & 18 \\
\hline & 090046-7 & 43 & 24 & 19 \\
\hline & 090046-9 & 46 & 24 & 22 \\
\hline & Average & 43.5 & 24 & $19.5 \mathrm{a}$ \\
\hline \multirow{12}{*}{$\mathrm{AAA}^{004} \times \mathrm{AAAA}^{007}$} & 090045-2 & 42 & 24 & 18 \\
\hline & $090045-4$ & 41 & 24 & 17 \\
\hline & 090045-5 & 41 & 24 & 17 \\
\hline & $090045-6$ & 40 & 24 & 16 \\
\hline & 090045-9 & 44 & 24 & 20 \\
\hline & 090045-20 & 41 & 24 & 17 \\
\hline & 090045-23 & 43 & 24 & 19 \\
\hline & $090045-24$ & 45 & 24 & 21 \\
\hline & $090045-26$ & 57 & 24 & 33 \\
\hline & 090045-30 & 43 & 24 & 19 \\
\hline & 090045-31 & 40 & 24 & 16 \\
\hline & Average & 43 & 24 & $19.4 \mathrm{a}$ \\
\hline
\end{tabular}

(Continued on next page) 
Table 3. (Continued) Chromosome numbers of the progenies obtained from autotriploid $\times$ diploid tetraploid crosses showing the contribution by the male and the female.

\begin{tabular}{lcccc}
\hline Type of crosses & Progeny code & $\begin{array}{c}\text { Chromosome } \\
\text { numbers }\end{array}$ & $\begin{array}{c}\text { Contributed by } \\
\text { male }^{\mathrm{z}}\end{array}$ & $\begin{array}{c}\text { Contributed by } \\
\text { female }^{\mathrm{y}}\end{array}$ \\
\hline AAA $^{004} \times$ AAAA $^{007}$ & $090089-2$ & 42 & 24 & 18 \\
& $090089-3$ & 40 & 24 & 16 \\
& $090089-5$ & 41 & 24 & 17 \\
& $090089-10$ & 44 & 24 & 20 \\
& $090089-12$ & 37 & 24 & 13 \\
$090089-14$ & 42 & 24 & 22 \\
& $090089-16$ & 46 & 24 & 19 \\
& $090089-19$ & 43 & 24 & 19 \\
& $090089-20$ & 43 & 24 & 20 \\
& $090089-23$ & 44 & 24 & 21 \\
& $090089-25$ & 45 & 24 & $18.5 \mathrm{a}$ \\
\hline
\end{tabular}

z Number of chromosomes contributed by male.

${ }^{\mathrm{y}}$ Number of chromosomes contributed by female.

${ }^{x}$ No significant difference between the number of the chromosomes contributed by female in these $3 \mathrm{x} \times 2 \mathrm{x} /$ $4 \mathrm{x}$ crosses at $P \leq 0.05$.

Chromosome preparation for progenies. The seedlings obtained by embryo rescue were numbered according to the crossing code and the lines of seedlings. For example, the eight lines of seedlings obtained from 090088 were numbered 090088-1, 090088-2, 090088-3, 090088-4, 090088-5, 090088-6, 090088-7, and 090088-8, respectively. Chromosome preparation was as for cultivars, but, because it was not always possible to obtain good root tips, the maximum number of progeny possible was analyzed.

\section{Results}

Chromosome preparation showed that four of the eight lily cultivars were diploid
$(2 n=2 x=24)$, two triploid $(2 n=3 x=36)$, Table 1). Pollen germination of diploid and tetraploid cultivars was $50 \%$ to $80 \%$, indicating that they were male-fertile, whereas pollen germination of triploid cultivars was less than $1 \%$, suggesting that they would not serve as acceptable male parents in a breeding program. Therefore, the two triploid cultivars were used as seed plants and pollinated with diploid and/or tetraploid pollen (Table 2).

The fruits of both $3 x \times 2 x$ and $3 x \times 4 x$ crosses developed well (Fig. 2). In all crosses, some ovules developed well, i.e., their endosperm or embryos were visible, so embryo sacs or embryos could be isolated (Table 2). Thirty-eight seedlings were obtained from and two were tetraploid $(2 n=4 x=48)$ (Fig. 1;
23 fruits of $3 x \times 2 x$ crosses and 96 seedlings from 20 fruits of $3 x \times 4 x$ crosses (Table 2 ). Only 090047 was not successful. Similar results were observed with three other triploid Asiatic lily cultivars in 2010 (data not shown). Based on these results, we concluded that male-sterile autotriploid lilies could be used as seed parents to cross with appropriate males.

Chromosome preparation showed that the progenies of these $3 x \times 2 \mathrm{x} / 4 x$ crosses were predominantly aneuploid with chromosome numbers as follows: $\mathrm{AAA}^{004} \times \mathrm{AA}^{005}$ progenies ranged from 27 to 39 ; $\mathrm{AAA}^{18} \times \mathrm{AA}^{26}$ from 28 to 32; those of $\mathrm{AAA}^{004} \times \mathrm{AAAA}^{001}$ (090046) from 40 to 46 ; $\mathrm{AAA}^{004} \times \mathrm{AAAA}^{007}$ (090045) from 40 to 57 ; and those of $\mathrm{AAA}^{004}$ $\times$ AAAA $^{007}$ (090089) from 37 to 46 (Table 3; Fig. 3). Based on the results, it was derived that the functional eggs contributed by triploids $\mathrm{AAA}^{004}$ and $\mathrm{AAA}^{18}$ in both $3 x \times 2 x$ and $3 x \times 4 x$ crosses were predominantly aneuploid with an average chromosome number of 18.9. Although the numbers of the chromosomes donated by the triploid lilies were apparently variable, analysis of variance gave no significant difference between the different crosses.

\section{Analysis and Discussion}

The present results could be well explained by theoretical analysis. Based on megasporogenesis of Fritillaria-type plants (Maheshwari, 1948), it is derived that the endosperm of $3 x \times$ $2 x$ crosses is $7 x$ and that of $3 x \times 4 x$ is $8 x$. It is clear, as shown in Figure 4, that a secondary nucleus of Fritillaria-type embryo sac is equal to the sum of the nuclei of four daughter cells
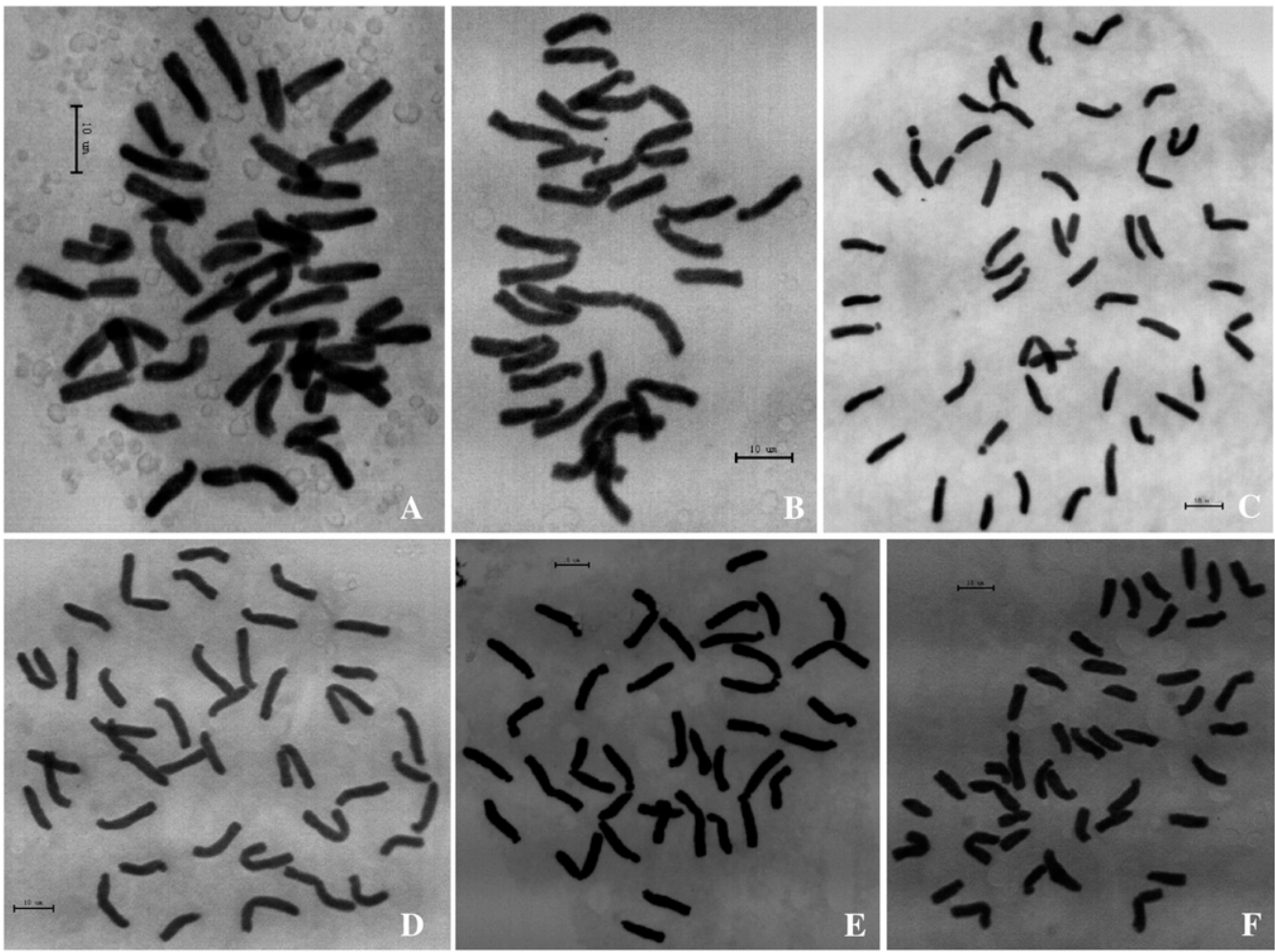

Fig. 3. The chromosomes at mitotic metaphase from root tips of the representative $3 x \times 2 x / 4 x$ progenies. $(\mathbf{A}) 090020-4(2 n=3 x+3=39)$, $(\mathbf{B}) 090010-5(2 n=$ $2 x+4=28),(\mathbf{C}) 090046-9(2 n=4 x-2=46),(\mathbf{D}) 090045-5(2 n=3 x+5=41),(\mathbf{E}) 090089-12(2 n=3 x+1=37)$, and $(\mathbf{F}) 090089-19(2 n=4 x-5=43)$. Bar $=10 \mu \mathrm{m}$. 


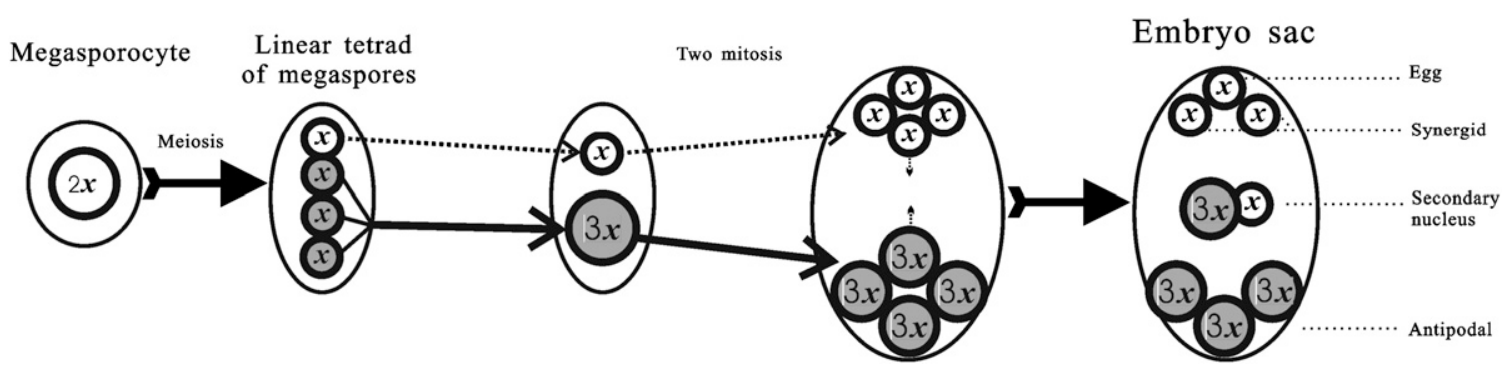

Fig. 4. Ideogram of megasporogenesis of Fritillaria-type embryo sac in Lilium. The arrows indicate the origin of the secondary nucleus, showing that the secondary nucleus is just equal to the sum of the nuclei of four daughter cells resulting from meiosis.

produced by a megaspore mother cell. When the megasporogenesis occurs in a triploid lily, its abnormal meiosis usually produces four aneuploid daughter cells. Because the sum of nuclear DNA of the four meiotic aneuploid daughter cells also originates from the duplication of the nuclear DNA of a megasporocyte, the secondary nucleus of triploid lily must be hexaploid $(6 x)$ because the secondary nucleus consists of the four meiotic daughter cells. This means that the ploidy level of a secondary nucleus of a Fritillaria embryo sac is invariably twice that of its somatic cells, whether this embryo sac forms through normal or abnormal meiosis. Therefore, the endosperm of $3 x \times 2 x / 4 x$ is euploid, and it is reasonable to consider that the euploid endosperm of $3 x \times$ $2 x / 4 x$ crosses is responsible for the survival of the aneuploid embryos resulting from these crosses.

The present results agree with previous reports (Barba-Gonzalez et al., 2006; Khan et al., 2009; Lim et al., 2003) that progenies of $3 x \times 2 x / 4 x$ crosses of Lilium are predominantly aneuploid as a result of aneuploid eggs (from $x$ to $3 x+3$ ) surviving (Fig. 5). In contrast, $3 x \times 2 x / 4 x$ crosses of most other plants usually produce euploid, i.e., diploid, tetraploid, and pentaploid progenies (Brandham, 1982; Carputo and Barone, 2005; Ramsey and Schemske, 1998). This could be explained by the difference of the secondary nucleus between Polygonum-type and Fritillaria-type embryo sacs, because endosperm is the primary reason for seed development or abortion (Birchler, 1993; Haig and Westoby, 1991; Johnston et al., 1980; Johnston and Hanneman, 1982; Scott et al., 1998). According to megasporogesis (Maheshwari, 1948), a triploid Polygonum-type plant usually produces an aneuploid egg $\left(1.5 x^{*}\right)$ and aneuploid secondary nucleus $\left(3.0 x^{*}\right)$, whereas a triploid Fritillaria-type plant produces an aneuploid egg cell $\left(1.5 x^{*}\right)$ but hexaploid secondary nucleus (6x) (Fig. 4). After double fertilization, as shown in Figure 6, both embryo and endosperm of $3 x \times 2 x / 4 x$ crosses in Polygonum-type plants are aneuploid. However, in Lilium $3 x \times 2 x / 4 x$ crosses, the embryo is aneuploid but the endosperm is euploid ( $7 x$ ) $8 x$ ), and it is likely that euploid endosperm would develop better than aneuploid endosperm. Therefore, in $3 x \times 2 x / 4 x$ crosses of Polygonum-type plants, only when eggs are euploid will both euploid endosperm and euploid embryo develop, and the surviving

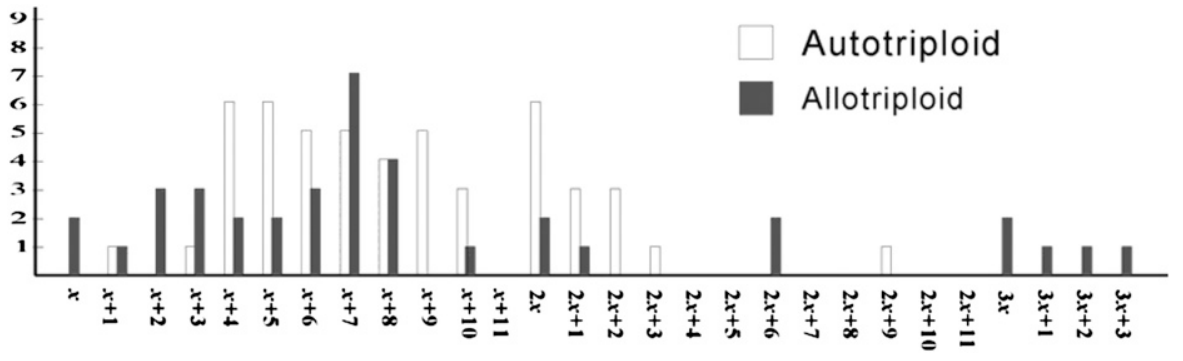

Fig. 5. Overall distribution of the frequency of eggs with different chromosome numbers produced by autoand allotriploid lilies. Data on autotriploids from the present study and those on allotriploids from previous research (Barba-Gonzalez et al., 2006; Khan et al., 2009; Lim et al., 2003).

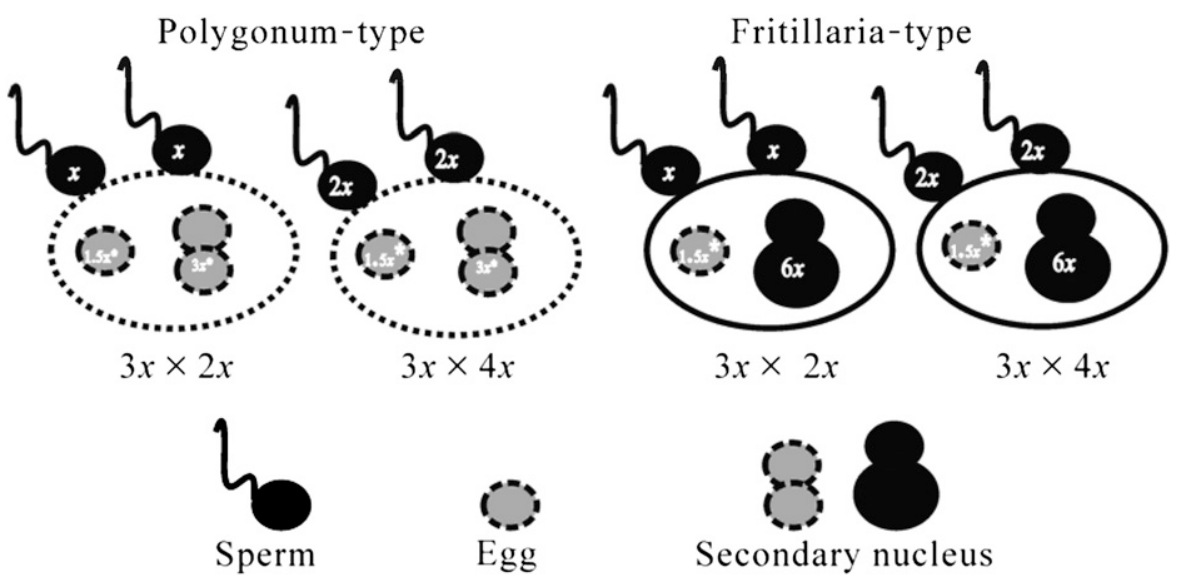

Fig. 6. Schematic comparison of ploidy level of sperm, egg, secondary nucleus, embryo, and endosperm in $3 x \times 2 x / 4 x$ crosses of Polygonum-type and Fritillaria-type plants. The dotted margin and gray of the aneuploid gamete and aneuploid secondary nucleus indicate that they are usually nonfunctional, and the solid margin and black of the euploid gamete and euploid secondary nucleus mean that they are usually functional.

plants will usually be euploid. However, in Fritillaria-type plants, whether eggs are euploid or aneuploid, their secondary nuclei are invariably euploid and their endosperm will likely develop and result in embryo survival. Further support comes from the fact that the chromosome numbers of most surviving eggs produced by triploid lilies are $\approx 1.5 x^{*}$ (Fig. 5), which is the same as the expected peak of aneuploid gametes produced by triploid lilies.

Endosperm balance number (EBN), proposed by Johnston et al. (1980) based on potato hybridization, has been used to explain the success or failure of interspecific and interploidy crosses of many plants (Carputo and Barone, 2005; Johnston and Hanneman, 1982). In $2 x \times 4 x, 4 x \times 2 x, 4 x \times 4 x, 2 x \times 5 x$, and $5 x \times 2 x$ crosses, Zhou (2007) noticed the difficulty in selfing the oryzalin-induced amphydiploid lilies, e.g., LALA $\times$ LALA. In contrast, whereas AA $\times$ LALA crosses are usually successful, their reciprocal crosses are not. This cannot be explained with EBN. It is possible that the DNA amount in primary endosperm of LALA $\times$ LALA and LALA $\times$ AA is so high that endosperm development is substantially hindered (Zhou, 2007).

In the present research, the AAA $\times$ AAAA crosses were more successful than AAA $\times$ AA. This is similar to our recent results of $\mathrm{LAA} \times \mathrm{AAAA}$ and $\mathrm{LAA} \times \mathrm{AA}$ crosses (unpublished data). The phenomenon can be explained by genomic imprinting, i.e., an excess dosage of paternal chromosomes promotes 
endosperm development (Köhler and WeinhoferMolisch, 2010; Scott et al., 1998).

Based on our results, we suggest that autotriploid lilies, regardless of their male sterility, could be used as a female to cross with appropriate diploid or tetraploid male. We also conclude that the progenies of $3 x \times 2 x / 4 x$ are aneuploid in Lilium rather than diploid or tetraploid like in Polygonum-type plants.

It is well known that a change in chromosome number can bring about large variation in morphological, physiological, and ecological characteristics. Because lily is usually propagated by scaling or tissue culture, the triploid lily may be a good potential source for breeding aneuploid lily cultivars.

\section{Literature Cited}

Barba-Gonzalez, R., K.B. Lim, M.S. Ramanna, and J.M. Van Tuyl. 2005a. Occurrence of 2n gametes in the F1 hybrids of Oriental $\times$ Asiatic lilies (Lilium): Relevance to intergenomic recombination and backcrossing. Euphytica 143:67-73.

Barba-Gonzalez, R., K.B. Lim, M.S. Ramanna, and J.M. Van Tuyl. 2005b. The occurrence of intergenomic recombination in the $\mathrm{F} 1$ hybrids of Oriental $\times$ Asiatic lily hybrids (Lilium) and its significance for genetic variation in the $\mathrm{BC} 1$ progenies as revealed by GISH and FISH analyses. Genome 48:884-894.

Barba-Gonzalez, R., B.H. Lokker, K.B. Lim, M.S. Ramanna, and J.M. Van Tuyl. 2004. Use of $2 n$ gametes for the production of sexual polyploids from sterile Oriental $\times$ Asiatic hybrids of lilies (Lilium). Theor. Appl. Genet. 109:1125-1132.

Barba-Gonzalez, R., R.A.A. Van Silfhout, M.S. Ramanna, R.G.F. Visser, and J.M. Van Tuyl. 2006. Progenies of allotriploids of Oriental $\times$ Asiatic lilies (Lilium) examined by GISH analysis. Euphytica 151:243-250.

Birchler, J.A. 1993. Dosage analysis of maize endosperm development. Annu. Rev. Genet. 27: 181-204.
Brandham, P.E. 1982. Inter-embryo competition in the progeny of autotriploid Aloineae (Liliaceae). Genetica 59:29-42.

Carputo, D. and A. Barone. 2005. Ploidy level manipulations in potato through sexual hybridization. Ann. Appl. Biol. 146:71-79.

Haig, D. and M. Westoby. 1991. Genomic imprinting in endosperm: Its effect on seed development in crosses between species, and between different ploidies of the same species, and its implications for the evolution of apomixis. Phil. Trans. R. Soc. B 333:1-13.

Johnston, S.A., T.M. den Nijs, S.J. Peloquin, and R.E. Hanneman, Jr. 1980. The significance of genic balance to endosperm development in interspecific crosses. Theor. Appl. Genet. 57: $5-9$.

Johnston, S.A. and R.E. Hanneman, Jr. 1982. Manipulations of endosperm balance number overcome crossing barriers between diploid species. Science 217:446-448.

Khan, N., S. Zhou, M.S. Ramanna, P. Arens, J. Herrera, R.G.F. Visser, and J.M. Van Tuyl. 2009. Potential for analytic breeding in allopolyploids: An illustration from Longiforum $x$ Asiatic hybrid lilies (Lilium). Euphytica 166: 399-409.

Kim, J.H., H.Y. Kyung, Y.S. Choi, J.K. Lee, M. Hiramatsu, and H. Okubo. 2006. Geographic distribution and habitat differentiation in diploid and triploid Lilium lancifolium of South Korea. J. Fac. Agr. Kyushu Univ. 51:239-243.

Köhler, C. and I. Weinhofer-Molisch. 2010. Mechanisms and evolution of genomic imprinting in plants. Heredity 105:57-63.

Lim, K.B., J.D. Chung, B.C.E. Van Kronenburg, M.S. Ramanna, J.H. De Jong, and J.M. Van Tuyl. 2000. Introgression of Lilium rubellum Baker chromosomes into L. Longiflorum Thunb.: A genome painting study of the F1 hybrid, $\mathrm{BC} 1$ and $\mathrm{BC} 2$ progenies. Chromosome Res. 8:119125.

Lim, K.B., M.S. Ramanna, J.H. De Jong, E. Jacobsen, and J.M. Van Tuyl. 2003. Evaluation of $\mathrm{BC} 2$ progenies derived from $3 x \times 2 x$ and $3 x \times$
$4 x$ crosses of Lilium hybrids: A GISH analysis. Theor. Appl. Genet. 106:568-574.

Maheshwari, P. 1948. The angiosperm embryo sac. Bot. Rev. 14:1-56.

McRae, E.A. 1990. American lily hybridizing-An historical review, p. 29-40. In: Hayward, A.F. (ed.). Lilies and related plants, supplement. Proc. 5th Int. Lily Conf., London, July 1989. Royal Hort. Soc.-Lily.

McRae, E.A. 1998. Lilies: A guide for growers and collectors. Timber Press, Portland, OR.

Ramsey, J. and D.W. Schemske. 1998. Pathways, mechanisms, and rates of polyploidy formation in flowering plants. Annu. Rev. Ecol. Syst. 29: 467-501.

Scott, R.J., M. Spielman, J. Bailey, and H.G. Dickinson. 1998. Parent-of-origin effects on seed development in Arabidopsis thaliana. Development 125:3329-3341.

Van Tuyl, J.M., K.B. Lim, and M.S. Ramanna. 2002a. Interspecific hybridization and introgression, p. 85-103. In: Vainstein, A. (ed.). Breeding for ornamentals: Classical and molecular approaches. Kluwer Academic Publishers, Dordrecht, The Netherlands.

Van Tuyl, J.M., I.W.G.M. Maas, and K.B. Lim. 2002b. Introgression in interspecific hybrids of lily. Acta Hort. 570:213-218.

Van Tuyl, J.M., A. Van Dijken, H.S. Chi, K.B. Lim, S. Villemoes, and B.C.E. Van Kronenburg. 2000. Breakthroughs in interspecific hybridization of lily. Acta Hort. 508:83-90.

Xie, S., M.S. Ramanna, and J.M. Van Tuyl. 2010. Simultaneous identification of three different genomes in Lilium hybrids through multicolour GISH. Acta Hort. 855:299-303.

Zhou, S. 2007. Intergenomic recombination and introgression breeding in Longiflorum $\times$ Asiatic lilies (Lilium). PhD diss., Wageningen University, The Netherlands.

Zhou, S., M.S. Ramanna, R.G.F. Visser, and J.M. van Tuyl. 2008. Genome composition of triploid lily cultivars derived from sexual polyploidization of Longiflorum Asiatic hybrids (Lilium). Euphytica 160:207-215. 